\title{
Studies on Capacity Expansion of Fuel Plants for Nuclear Research Reactors
}

\author{
Miguel Luiz Miotto Negro', Michelangelo Durazzo', Marco Aurélio de Mesquita², \\ Elita Fontenele Urano de Carvalho ${ }^{1}$, Roberto Navarro de Mesquita', Delvonei Alves de Andrade ${ }^{1}$ \\ ${ }^{1}$ Instituto de Pesquisas Energeticas e Nucleares (Nuclear and Energy Research Institute), São Paulo, Brazil \\ ${ }^{2}$ Escola Politecnica da Universidade de Sao Paulo (Polytechnic School of Sao Paulo University), São Paulo, Brazil \\ Email: mlnegro@ipen.br, mdurazzo@ipen.br, mamesqui@usp.br, elitaucf@ipen.br, mavarro@ipen.br, delvonei@ipen.br
}

How to cite this paper: Negro, M.L.M., Durazzo, M., de Mesquita, M.A., de Carvalho, E.F.U., de Mesquita, R.N. and de Andrade, D.A. (2018) Studies on Capacity Expansion of Fuel Plants for Nuclear Research Reactors. World Journal of Nuclear Science and Technology, 8, 38-53.

https://doi.org/10.4236/wjnst.2018.82005

Received: February 2, 2018

Accepted: April 6, 2018

Published: April 9, 2018

Copyright $\odot 2018$ by authors and Scientific Research Publishing Inc. This work is licensed under the Creative Commons Attribution International License (CC BY 4.0).

http://creativecommons.org/licenses/by/4.0/

\begin{abstract}
The demand for nuclear fuel for research reactors is rising worldwide. Thus, the production facilities of this kind of fuel need reliable guidance on how to augment their production in order to meet the increasing demand efficiently and safely. We proposed a specific procedure for increasing production capacity. That procedure was tested with data from a real plant, which produces plate-type fuel elements loaded with $\mathrm{LEU} \mathrm{U}_{3} \mathrm{Si}_{2}-\mathrm{Al}$ fuel. The test was made by means of discrete event simulation, and the results indicated the proposed procedure is efficient in raising production capacity.
\end{abstract}

\section{Keywords}

Fabrication of Uranium Silicide Fuel, Plate-Type Fuel Elements, Nuclear Research Reactors, Production Capacity Expansion

\section{Introduction}

There is a trend in several countries to increase knowledge of nuclear technology and also to expand the benefits provided by the pacific use of this technology [1] [2]. Moreover, some sectors of the nuclear industry struggle to amplify the public acceptance of this technology [3] [4].

Nuclear research reactors are responsible for a relevant portion of the generation of knowledge of nuclear technology as well as for a part of the benefits generated by the use of its techniques [5] [6]. The spread of nuclear applications implies a growing utilization of nuclear research reactors [7]. That growth in turn causes an increase in the demand for nuclear fuels for research reactors [8].

Generally speaking, the production of nuclear fuels for research reactors has the following characteristics: 
- small scale,

- exclusive for one reactor,

- production facility located near the corresponding user, and

- non-commercial transactions.

The rise in the demand for nuclear fuel for research reactors poses several questions for production facilities managers. Among these issues, the increase in production capacity is where we seek solutions for the remaining queries. Thus, it is of great interest to study how to enhance the production capacity of this class of fuel. The reasons exposed so far underline the convenience of having a safe and reliable method of expanding the production capacity of nuclear fuel for research reactors. The same reasons guided us in establishing the objective of this paper, which is to propose and test a procedure for expanding the production capacity of nuclear fuel for research reactors.

The originality of this work is due to the scarcity of scientific publications about this subject matter. Such scarcity has been proven through searches in two databases on two different dates and by using different search inputs. Until the date of submission of this paper, we did not find a publication similar to the theme of this work. We searched Web of Science and Scopus in the years 2015, 2016 and 2017, and we used the following expressions for the search:

- capacity planning of nuclear fuel for research reactors;

- capacity planning for production of nuclear fuel for research reactors;

- increasing capacity for production of nuclear fuel for research reactors;

- methods of increasing capacity for production of nuclear fuel for research reactors;

- production of nuclear fuel for research reactors.

We did get some results from the abovementioned databases. However, the publications only related to parts of our theme, for instance, the detailed technical study of the production path or the optimization of refueling a Pressure Water Reactor. No results coincide with our theme. The lack of coincidence of published scientific works leads to the conclusion that this paper is original.

\section{Literature Review}

\subsection{Manufacturing}

Many of the previously mentioned questions are studied by the area of operations management [9] [10]. That body of knowledge lies on the interface between natural and social sciences [11]. Any manufacturing plant is therefore strongly influenced by the decisions of its managers.

\subsubsection{Plant}

The focus of this work is the expansion of the production capacity of plants that produce nuclear fuel for research reactors. Thus, we started by reviewing the literature that deals with capacity enlargement of general manufacturing plants. That content is easily found in operations management literature [12] [13] [14]. After reviewing these general concepts, we adapted them to the specific case of plants that produce nuclear fuel for research reactors. That adaptation led to the 
specific procedure presented in Section 3.1.

The mentioned authors present several concepts and methods for the generic case of designing, modeling and analyzing manufacturing capacity growth. Such methods have several points in common. We set a correlation among those points and adopted this correlation as the general procedure for capacity expansion for this paper, which is presented as follows:

\section{General procedure}

1) establish organizational and production strategies;

2) analyze demand, product, materials and processes;

3) identify bottlenecks;

4) set changes to the processes;

5) if necessary, establish a new layout;

6) implement the changes; and

7) check the efficacy of the changes.

The general procedure is detailed below.

The statement of the organization strategy is a task for the high managerial level, and it affects all areas of the corporation [9] [10]. Production is an important part of any manufacturing company, and it has to determine its own strategy. Production strategy clearly must be aligned with organizational strategy.

The market is the element that sets the demand. In our case study, the market and the customer are known, and both of them are the organization itself. We assumed the demand will be as much as the factory will produce in each of the scenarios described in the following sections. Furthermore, we postulated that the plant will produce only one product. That product is a plate-type Fuel Element (FE) containing LEU $\mathrm{U}_{3} \mathrm{Si}_{2}$ - $\mathrm{Al}$ fuel, whose materials and processes are outlined in Section 2.2.

The so called "bottleneck" is a process that belongs to the Critical Production Path. It has the highest cost among all processes and is the process that takes the longest time to be executed, according to several authors [15] [16] [17]. Thus, the bottleneck is the process that most influences the total production throughput. It is for this reason that the bottleneck needs to be carefully studied. The study of the bottleneck and its impacts on the production flow may indicate the need of changing other processes. Such changes should not only be studied individually, but also in connection with a possible change in layout, aiming to balance the whole production line.

A logical layout is essential for the material's flow to be efficient and safe throughout the factory [16] [17] [18] [19]. This way, after introducing the changes in the processes, a new flow of intermediate products will be established, at least in some parts of the plant.

All activities cited previously are design activities. At this point we should execute the prior definitions in the real plant. Moreover, the performance of all processes must be measured directly on the factory floor [13] [20].

Specifications regarding workforce and production planning and control de- 
pend on the type of production flow and the layout, whose final settings are not within the scope of this paper. Besides, the study of these elements is quite extensive [21] [22]. Thus, the only remark regarding these elements is the assumption that there will be enough labor for the development of the scenarios proposed in the sections below.

\subsection{Nuclear Engineering}

The technical aspects demanded some scope delimitations for the nuclear fuel in focus. The first one refers to the type of fuel, as there are several types of nuclear fuel for research reactors [23]. We selected the uranium silicide fuel $\left(\mathrm{U}_{3} \mathrm{Si}_{2}\right)$ because of its large use in research reactors, its good capacity of uranium loading and its excellent performance [24].

Another scope delimitation refers to the route of production of $\mathrm{U}_{3} \mathrm{Si}_{2}$, since this fuel can be obtained by several processes [25] [26]. We chose the route that includes the hydrolysis of uranium hexafluoride $\left(\mathrm{UF}_{6}\right)$ for the following reasons:

- relative simplicity;

- production of small quantities of intermediate products, which contributes to safety;

- the increase in demand will probably also affect factories that use this production route;

- The data available for this work came from a facility that uses this route; and

- Lack of specific literature to guide capacity increase on this production route.

On the other hand, the level of uranium enrichment currently present in the fuel of most nuclear research reactors corresponds to the mass concentration of $19.75 \% \pm 0.25 \%$ of the isotope ${ }^{235} \mathrm{U}$ [23]. This value is known as low enriched uranium (LEU). Based on these facts, we selected LEU for the uranium concentration in the fuel considered in this work. In addition, we adopted the value of $3.2 \mathrm{~g} / \mathrm{cm}^{3}$ for the uranium density in the fuel, because it is the most common one in nuclear research reactors [24] [27] [28].

In its production processes, $\mathrm{U}_{3} \mathrm{Si}_{2}$ is milled and its powder is mixed with aluminum (Al) powder. This mixture of powders is pressed. The pressed piece is then surrounded by aluminum plates. Thus, a considerable amount of aluminum is disposed in the vicinity of $\mathrm{U}_{3} \mathrm{Si}_{2}$ molecules. In this situation it is said that $\mathrm{U}_{3} \mathrm{Si}_{2}$ is dispersed in an Al-matrix. This results in the nomenclature of the selected fuel for this work: low enriched uranium silicide and dispersed in aluminum matrix, generally referred to as $\mathrm{LEU} \mathrm{U}_{3} \mathrm{Si}_{2}-\mathrm{Al}$ [29] [30].

The final scope delimitation refers to the vector responsible for the availability of nuclear fuel in the research reactor. In this study we considered the plate type fuel element, since this is the type of fuel element most commonly used in nuclear research reactors [31].

\subsection{Simulation Modeling}

Several authors [32] [33] [34] stress the benefits of modeling manufacturing sys- 
tems, explaining why we have included simulation in this paper. Some of those benefits are the following:

- Consideration of the interactions of parts of a system;

- Generation of several performance improvement alternatives; and

- Possibility of studying scenarios of changes.

There are several ways of modeling manufacturing systems. Below is the step-by-step guide we used to build our simulation model as well as to run the simulation itself. This guide is an adaptation of some modeling methodologies found in simulation modeling literature [35] [36] [37].

\section{Simulation modeling guide}

1) Problem analysis and information collection

2) Data collection

3) Model construction

4) Model verification and validation

5) Designing and conducting simulation experiments

6) Output analysis

We used discrete event simulation (DES) due to the stochastic nature of the production processes of nuclear fuel and because DES is successfully employed in different areas of manufacturing like batch processes, continuous processes, capacity planning, job floor scheduling, and others [38]. There are sundry tools for DES simulation, such as Simul8, ProModel and AutoMod [39]. In this work we used the academic version of ARENA ${ }^{\circledR}$ software [40] because it allows the simulation of practically any scenario of material flow through sets of processes and because its academic version is available to the University of São Paulo by means of its agreement with Rockwell Automation.

\section{Methods}

The methodology of the work described in this paper consists of the following main components:

1) Proposal of a specific procedure for expansion of the production capacity, and

2) Testing and evaluation of the proposed procedure.

\subsection{Specific Procedure}

In this Section we propose a specific procedure for expansion of the production capacity of LEU $\mathrm{U}_{3} \mathrm{Si}_{2}-\mathrm{Al}$ fuel. The specific procedure is a conformation of the general procedure mentioned in Section 2.1.1, and it contains the following steps:

Specific procedure

1) Establish organizational and production strategies;

2) Identify bottlenecks;

3) Increase the bottleneck's capacity;

4) Check for the risk of criticality in the new set up; and 
5) Check if the demand is met.

Item 2 of the general procedure does not belong to the specific procedure because demand has its own treatment, as we will discuss later. Product, materials and processes are known and were discussed in Section 2.2. Items 6 and 7 of the general procedure go beyond the scope of this work and therefore are not included in the specific procedure.

With respect to layout, we must pay careful attention to criticality. This means that we must avoid the risk of nuclear fission of the intermediate materials during the various productive processes because most of these materials contain enriched uranium. Thus, if there is a criticality risk after step 3 of the specific procedure, we must find new solutions and check for the criticality of the new solutions. Only if the risk of criticality lies within its margins of safety in step 4 can we proceed to step 5 .

For the scope of this work, we assume that any change in layout will only be made with due enforcement of IAEA and CNEN standards concerning criticality [41] [42] [43]. Such enforcement means we consider that the factory works in its sub-critical state in all the scenarios presented in Section 4. This implies that Step 4 will always be safe regarding criticality for each and every change of layout proposed in this paper.

\subsection{Testing and Evaluation of the Specific Procedure}

In order to test the specific procedure of Section 3.1 we conducted a case study in an existing plant, which already produces $\mathrm{LEU} \mathrm{U}_{3} \mathrm{Si}_{2}-\mathrm{Al}$ fuel for research reactors and performs $\mathrm{UF}_{6}$ hydrolysis. That factory belongs to IPEN, the Nuclear and Energy Research Institute, which is part of CNEN, the Brazilian National Commission on Nuclear Energy and is located in São Paulo, Brazil. We applied the proposed procedure to IPEN's nuclear fuel plant and used real data from that plant in order to run computer simulations of its processes in different production scenarios.

Testing of the proposed procedure was done by means of the execution of the following three activities:

- Application of the proposed specific procedure to the nuclear fuel plant at IPEN;

- Establishment of layout and production scenarios; and

- Running discrete event simulation of each scenario.

All three activities for testing the proposed procedure were done using real data from the nuclear fuel plant at IPEN. The evaluation of the proposed procedure was done by comparing the simulation's results. That comparison led to useful conclusions, indicating that the objectives of this paper were met.

\subsubsection{Application of the Specific Procedure to the Nuclear Fuel Plant at IPEN}

\subsubsection{Step 1: Establish Organizational and Production Strategies}

The first step of the proposed procedure from Section 3.1 is to establish orga- 
nizational and production strategies. Such strategies are usually managerial decisions; the ones corresponding to the nuclear fuel plant at IPEN are listed below.

- The institution produces and consumes its own nuclear fuel;

- The institution does not supply any third party with its nuclear fuel;

- The only fuel produced is $\mathrm{U}_{3} \mathrm{Si}_{2}$ - $\mathrm{Al}$ enriched at $20 \%$ of ${ }^{235} \mathrm{U}$; and

- Only one type of FE is manufactured.

The list of organizational and production strategies of the nuclear fuel plant at IPEN determines that supply is to only one market and exclusively to one single customer. In this case, the customer is the institution itself. The named strategies are among the boundary conditions of this work. Thus, Step 1 is the basis for the development of the other steps of the proposed procedure. In order to set the scope of this study, we do not consider making changes to Step 1. Thus, the strategies from the list above fulfill Step 1 of the proposed procedure.

\subsubsection{Step 2: Identify Bottlenecks}

One basic condition to identify bottlenecks is to thoroughly understand the processes. For that reason we started this work with the personal mapping of all processes of IPEN's nuclear fuel plant. We studied all departments of the plant and recorded the processing times, the work procedures, the safety measures, the materials and equipment used, the layout, and the number of workers as well as the flows of material, people and information. This generated a considerable amount of information, which is presented in the following section.

\subsection{Process Mapping and Data Gathering}

The nuclear fuel plant at IPEN is divided into four work centers (WC). Tables 1-4 present the production activities carried out in each of those centers, the process times of all activities, and the numbering of the activities in ascending order of execution. The sequence of execution of the processes was noted during personal observation on the factory floor; it was also obtained from the literature [30]. The ascending order of execution cannot be changed because of changes in layout or capacity expansion. This is due to the fact that all activities listed in Tables 1-4 depend on the execution of the previous activity mentioned in the same tables. Thus, all changes addressed in this paper keep the order of execution in its ascending sequence presented in Tables 1-4. Details about all processes can be easily found in the correspondent literature [27] [31].

Processes and times presented in Tables 1-4 reflect the actual material flow on the factory floor. The steps were measured in person during their execution and directly at each work center, each work station and each piece of equipment at IPEN's nuclear fuel factory.

Table 1 presents the processes that occur at Work Center 1 . Hydrolysis of UF is carried out in this center. This is the center that has the highest risk of criticality, due to the use of water for the process of hydrolysis. This fact requires careful planning before any changes in layout can occur.

Table 2 presents the processes executed at Work Center 2 of IPEN's nuclear fuel plant. This center is responsible for the production of ingots of the $\mathrm{U}_{3} \mathrm{Si}_{2}$ intermetallic alloy. 
Table 1. Processes at work center 1.

\begin{tabular}{|c|c|c|}
\hline No. & Processes & Time (hours) \\
\hline 1 & Reception of cylinders containing $\mathrm{UF}_{6}$ & 0.80 \\
\hline 2 & Preparation for $\mathrm{UF}_{6}$ transfer & 2.45 \\
\hline 3 & $\mathrm{UF}_{6}$ transfer from the cylinder to the ampoule & 3.66 \\
\hline 4 & Preparation for $\mathrm{UF}_{6}$ hydrolysis & 2.54 \\
\hline 5 & $\mathrm{UF}_{6}$ hydrolysis & 3.74 \\
\hline 6 & Preparation for $\mathrm{UF}_{4}$ precipitation & 1.70 \\
\hline 7 & $\mathrm{UF}_{4}$ precipitation & 4.28 \\
\hline 8 & $\mathrm{UF}_{4}$ washing and filtration & 1.83 \\
\hline 9 & $\mathrm{UF}_{4}$ drying & 17.50 \\
\hline 10 & $\mathrm{UF}_{4}$ dehydration & 6.50 \\
\hline & TOTAL & 45.00 \\
\hline
\end{tabular}

Table 2. Processes at work center 2.

\begin{tabular}{clc}
\hline No. & \multicolumn{1}{c}{ Processes } & Time (hours) \\
\hline 11 & Crucible load with $\mathrm{UF}_{4}-\mathrm{Mg}$ & 2.35 \\
12 & $\mathrm{UF}_{4}$ reduction to metallic uranium & 7.28 \\
13 & Crucible disassembly and density measurement & 0.84 \\
14 & Stripping of metallic uranium & 0.56 \\
15 & Crucible load with metallic uranium and $\mathrm{Si}$ & 1.18 \\
16 & Melting of the intermetallic alloy $\mathrm{U}_{3} \mathrm{Si}_{2}$ & 8.20 \\
17 & Density measurement of the $\mathrm{U}_{3} \mathrm{Si}_{2}$ ingot & 0.34 \\
& $\quad$ TOTAL & 20.75 \\
\hline
\end{tabular}

Table 3. Processes at work center 3.

\begin{tabular}{clc}
\hline No. & \multicolumn{1}{c}{ Processes } & Time (hours) \\
\hline 18 & ${\text { Grinding of } \mathrm{U}_{3} \mathrm{Si}_{2} \text { and classification of its powder }}_{1.87}$ & 1.87 \\
19 & $\mathrm{U}_{3} \mathrm{Si}_{2}$ homogenization with $\mathrm{Al}^{0}$ & 6.28 \\
20 & Pressing of the mix $\mathrm{U}_{3} \mathrm{Si}_{2}$ and $\mathrm{Al}^{0}$, producing fuel cores & 2.40 \\
21 & Fuel core dimensional control & 2.76 \\
22 & Fuel core degassing $\quad$ TOTAL & 3.69 \\
& & 17.00 \\
\hline
\end{tabular}

Table 3 presents the production processes at Work Center 3 of IPEN's nuclear fuel plant. The end product of this center is the fuel core, made by cold pressing the mixture of powders of $\mathrm{U}_{3} \mathrm{Si}_{2}$ and $\mathrm{Al}^{0}$.

Table 4 presents all processes executed at Work Center 4 . This center is responsible for the reception of several parts, as follows: 
Table 4. Processes at work center 4.

\begin{tabular}{|c|c|c|}
\hline No. & Processes & Time (hours) \\
\hline 23 & Reception of aluminum boards & 1.67 \\
\hline 24 & Cladding and framing preparation & 3.28 \\
\hline 25 & Cladding and framing stripping & 4.55 \\
\hline 26 & Assembly of the set & 1.12 \\
\hline 27 & Welding of the set & 1.50 \\
\hline 28 & Hot rolling and annealing & 8.83 \\
\hline 29 & Blister inspection & 0.54 \\
\hline 30 & Cold rolling & 1.08 \\
\hline 31 & Initial cut & 3.43 \\
\hline 32 & Four processes on fuel plates (FP) & 8.37 \\
\hline 33 & Final cut & 2.86 \\
\hline 34 & Surface treatment & 2.21 \\
\hline 35 & Dimensional inspection and second radiography of FP & 3.89 \\
\hline 36 & Scratching test & 1.67 \\
\hline 37 & Stripping of FP and FE components & 6.33 \\
\hline 38 & FE assembly & 6.82 \\
\hline 39 & Quality control & 3.37 \\
\hline 40 & Nozzle fixation & 1.06 \\
\hline 41 & Handling pin fixation & 0.86 \\
\hline 42 & FE dimensional control & 0.96 \\
\hline 43 & FE cleaning and packing & 1.12 \\
\hline \multirow[t]{2}{*}{44} & Delivery of the finished FE & 0.48 \\
\hline & TOTAL & 56.50 \\
\hline
\end{tabular}

- Fuel cores from Work Center 3;

- Aluminum boards from external suppliers; and

- Finished FE components also from external suppliers.

In Table 4 the mentioned "set" is composed by the joining of a fuel core, a frame plate and two cladding plates. Still in Table 4, process number 32 is named as "Four processes on fuel plates (FP)" because it comprises the processes of the first radiography of FP, searching for defects on FP, FP's tracing, and FP's identification. These four processes happen at the same workstation, so they cannot be split. Processes 23, 24 and 25 from Table 4 are executed simultaneously with processes of Work Center 3. Thus processes 23, 24 and 25 do not belong to the Critical Production Path and their times were not considered in the simulation.

\subsection{The Bottleneck}

Tables 1-4 reflect the initial situation of the nuclear fuel plant at IPEN. They 
are the basis to find the bottleneck in the initial production set up of that factory. The mentioned initial situation is safe against criticality because it processes only one production lot at a time in each work center. In other words, a production lot can only enter a given work center after the previous lot has already been processed and released by that work center. These facts allow us to consider each work center as a single processing unit, whose processing times are the total times of each work center, which are presented in the last line of Tables 1-4.

With the whole factory having only four processing units, we identify the bottleneck as being Work Center 4 (WC 4) because its total processing time is the highest of the four work centers. However, we know that each work center involves several processes. Thus, we look for the process with the highest time within WC 4 and find it corresponds to process number 28 , hot rolling and annealing, mentioned in Table 4 . This is the bottleneck we work with. In this way, we accomplished Step 2 of the proposed procedure from Section 3.1.

\subsubsection{Step 3: Increase the Bottleneck's Capacity}

In order to increase the bottleneck's capacity, we increased the capacity of the single process of the bottleneck itself, whose methods can be found in numerous references [16] [17] [19]. In this paper we assume that the bottleneck has its capacity doubled, what is usually done by means of acquiring new equipment. We considered that doubling the capacity of the bottleneck has two effects:

- The bottleneck's process takes half the time, and

- The total processing time of the work center where the bottleneck is located is decreased.

Thus, we fulfilled Step 3 of the proposed procedure from Section 3.1.

\subsubsection{Step 4: Check for the Risk of Criticality in the New Set Up}

The increase of the bottleneck's capacity established in the former step imposes changes in the production line and in its layout. Such changes alter the risk of criticality of the plant. We therefore need to calculate the new criticality level and verify that it lies within the limits imposed by the regulations of nuclear safety [41] [42] [43]. If the new criticality level is higher than that allowed by the nuclear safety authority, we need to go back to Step 3 and find a new way of increasing the bottleneck's capacity.

The calculation of the risk of criticality is an extensive task, which usually demands the work of teams of specialists. Therefore, we consider that any increase in the production capacity mentioned in this paper will generates a sub-critical system. Thus, we fulfilled Step 4 from the proposed procedure from Section 3.1.

\subsubsection{Step 5: Check if the Demand Is Met}

Below are some of the consequences of increasing the bottleneck's capacity:

- the flow of materials increases in the part of the plant where the original bottleneck was located;

- the production level of the whole plant increases; and

- a new bottleneck appears in some other part of the plant.

If the new production level meets the demand, we can stop the activity of increasing capacity and focus on balancing the materials flow affected by the new 
bottleneck.

If the new production level does not meet the demand, we need to increase the production capacity again. This is done by replicating the proposed procedure, returning to Step 2 and this time focusing on the new configuration of the plant. We do not retake the proposed procedure from Step 1 because we do not consider any change in Step 1, as mentioned in Section 3.2.1.1.

\subsubsection{Establishment of Layout and Production Scenarios}

As previously mentioned, one of the consequences of the increase of the bottleneck's capacity is the change in layout. We named each of the layout changes as scenarios because they affect the material flow in the whole production plant as well as the production level. We established ten scenarios of growing production capacity. Below we present the suppositions adopted for all scenarios.

1) Supply of $\mathrm{UF}_{6}$ is continuous and sufficient;

2) The quality of $\mathrm{UF}_{6}$ is good enough to run all processes of the plant;

3) There is no waste due to quality non-compliance in the whole factory;

4) Manpower is sufficient and trained to perform all scenarios;

5) Production time is 210 working days per year, corresponding to approximately ten production months per year; and

6) Daily operation time is eight hours per working day.

\subsubsection{Running Discrete Event Simulation with Real Data from the Fuel Plant at IPEN}

The construction of the simulation model and the execution of our simulation were carried out following the guide exposed in Section 2.3. Steps 1 and 2 of that guide were executed as explained in Section 3.2.1.2.1. Step 3 was executed according to the layout of each scenario. Step 4 was conducted by means of comparison of Scenario 1 with the initial situation of the nuclear fuel plant at IPEN. The model built in Step 3 proved to be in accordance with the plant's current situation, thus accomplishing Step 4 of the guide from Section 2.3. Steps 5 and 6 of that guide correspond to Section 4 of this paper.

We set the simulation period of each scenario as one year. We did so with the aim of considering the several different situations that happen during one year. The simulation was replicated ten times for each scenario, thus simulating ten years of production under each scenario.

\section{Results}

\section{Scenario 1}

As mentioned previously, the initial status of the fuel plant at IPEN is the source of data for our DES, therefore being the reference for the DES too. That status is represented by Tables $1-4$, and we called it Scenario 1. The result of DES of Scenario 1 is $28 \mathrm{FE}$ produced in one year. For the identification of the bottleneck of Scenario 1 we followed the procedures from previous sections. Thus we identified the bottleneck of Scenario 1 as hot rolling and annealing, 
which is process number 28 of WC 4.

\section{Scenario 2}

According to the previous sections, we doubled the capacity of the process of hot rolling and annealing. Thus, that process is now done in half the time, i.e., 4.415 hours. This new time shapes Scenario 2. At this point we ran DES for Scenario 2 and its result was $30 \mathrm{FE}$ per year. In order to identify the bottleneck of Scenario 2, we followed the proceedings from previous sections and found that its bottleneck is the process number 32 of Table 4, four processes on FP, executed in WC 4.

\section{Scenarios 3 to 10}

We executed the same procedures of Scenario 2 and found respectively new times, yearly production and new bottlenecks for Scenarios 3 until 10, whose results and comparisons are presented in Table 5 and Table 6.

Table 5. Lead times in working hours.

\begin{tabular}{cccccc}
\hline Scenario & WC 1 & WC 2 & WC 3 & WC 4 & Plant \\
\hline 1 & 5.63 & 2.59 & 2.13 & 7.06 & 17.41 \\
2 & 5.63 & 2.59 & 2.13 & 6.51 & 16.86 \\
3 & 5.63 & 2.59 & 2.13 & 5.99 & 16.34 \\
4 & 5.63 & 2.59 & 2.13 & 5.56 & 15.91 \\
5 & 4.53 & 2.59 & 2.13 & 5.56 & 14.81 \\
6 & 4.53 & 2.59 & 2.13 & 5.17 & 14.42 \\
7 & 4.53 & 2.59 & 2.13 & 4.89 & 14.14 \\
8 & 4.53 & 2.59 & 2.13 & 4.62 & 13.87 \\
9 & 4.53 & 2.59 & 2.13 & 4.38 & 13.63 \\
10 & 3.98 & 2.59 & 2.13 & 4.38 & 13.08 \\
\hline
\end{tabular}

Table 6. Simulation results and their comparisons.

\begin{tabular}{cccccc}
\hline \multirow{2}{*}{ Scenario } & Bottleneck & & Production & \multicolumn{2}{c}{ Percentage raise regarding } \\
\cline { 5 - 6 } & Process & Nr. & (FE per year) & Previous scenario & Scenario 1 \\
\cline { 5 - 6 } 1 & Hot rolling & 28 & 28 & - & - \\
2 & Four processes & 32 & 30 & 7 & 7 \\
3 & FE assembly & 38 & 33 & 10 & 18 \\
4 & UF $_{4}$ drying & 9 & 34 & 3 & 21 \\
5 & Stripping & 37 & 36 & 6 & 29 \\
6 & Hot rolling & 28 & 38 & 6 & 36 \\
7 & Four processes & 32 & 40 & 5 & 43 \\
8 & Dimensional inspection & 35 & 42 & 5 & 50 \\
9 & UF & & & 5 & 50 \\
10 & Initial cut & 31 & 45 & 7 & 61 \\
\hline
\end{tabular}


In Table 5, we can see that all four Work Centers keep their original number. Since all processes occur within some Work Center, then the increase in capacity of a given process does not change the Work Center where this process is performed. Therefore, the differences from one scenario to the next are the reduction of the lead time of the Work Center where the bottleneck was located and the reduction of the total lead time of the plant.

\section{Conclusions}

Table 6 shows that the proposed procedure for expansion of productive capacity yields capacity growth. The way of expanding the bottleneck's capacity proved to be effective as well. The aforementioned way was to double the capacity of the bottleneck under the conditions mentioned in the previous sections. The comparison of production between Scenarios 1 and 10 shows that an increase of $61 \%$ is possible.

Therefore, we proved that the proposed procedure does increase production capacity. The conclusions of the present study may thus be used by IPEN's nuclear fuel plant managers as guidelines for the decision-making process.

As suggestions for future works, we mention the addition of data, which may include costs, itemized layout, chemical equations and the critical uranium mass.

\section{Acknowledgements}

We thank the workers of IPEN's fuel plant for sharing their knowledge with us and for giving us data regarding their activity. We are grateful to $\mathrm{CNPq}$ for the research grant 310274/2012-5 provided for this work. We also thank Prof. Robert Caudle Garner for his help with the English language.

\section{References}

[1] Chen, T., Chen, G., Yang, S., Zhao, Y., Ha, Y. and Ye, Z. (2015) Recent Developments in the Application of Nuclear Technology on Agro-Food Quality and Safety Control in China. Food Control, 1-7.

[2] Cheng, X., Batta, A., Bandini, G., Roelofs, F., Van Tichelen, K., Gerschenfeld, A., Prasser, M., Papukchiev, A., Hampel, U. and Ma, W.M. (2015) European Activities on Crosscutting Thermal-Hydraulic Phenomena for Innovative Nuclear Systems. Nuclear Engineering and Design, 290, 2-12. https://doi.org/10.1016/j.nucengdes.2014.11.007

[3] Hong, S., Bradshaw, C.J.A. and Brook, B.W. (2014) Nuclear Power Can Reduce Emissions and Maintain a Strong Economy: Rating Australia's Optimal Future Electricity-Generation Mix by Technologies and Policies. Applied Energy, 136, 712-725. https://doi.org/10.1016/j.apenergy.2014.09.062

[4] Turcanu, C., Schröder, J., Meskens, G., Perko, T., Rossignol, N., Carlé, B. and Hardeman, F. (2016) Like a Bridge over Troubled Water-Opening Pathways for Integrating Social Sciences and Humanities into Nuclear Research. Journal of Environmental Radioactivity, 153, 88-96. https://doi.org/10.1016/j.jenvrad.2015.12.009

[5] Almaz, E., Stone, S., Blue, T.E. and Heremans, J.P. (2010) The Effects of Neutron Irradiation and Low Temperature Annealing on the Electrical Properties of Highly 
Doped 4H Silicon Carbide. Nuclear Instruments and Methods in Physics Research Section A: Accelerators, Spectrometers, Detectors and Associated Equipment, 622, 200-206. https://doi.org/10.1016/j.nima.2010.06.211

[6] Huseynov, E.M. (2017) Investigation of the Agglomeration and Amorphous Transformation Effects of Neutron Irradiation on the Nanocrystalline Silicon Carbide (3C-SiC) Using TEM and SEM Methods. Physica B: Condensed Matter, 510, 99-103. https://doi.org/10.1016/j.physb.2017.01.024

[7] Pegonen, R., Bourdon, S., Gonnier, C. and Anglart, H. (2016) Hot Fuel Element Thermal-Hydraulics in the Jules Horowitz Reactor. Nuclear Engineering and Design, 300, 149-160. https://doi.org/10.1016/j.nucengdes.2016.01.031

[8] Choo, K.N., Cho, M.S., Yang, S.W. and Park, S.J. (2014) Contribution of Hanaro Irradiation Technologies to National Nuclear R\&D. Nuclear Engineering and Technology, 46, 501-512. https://doi.org/10.5516/NET.07.2014.006

[9] Choi, S. and Messinger, P.R. (2014) The Role of Fairness in Competitive Supply Chain Relationships: An Experimental Study. European Journal of Operational Research, 251, 798-813. https://doi.org/10.1016/j.ejor.2015.12.001

[10] Cerchione, R. and Esposito, E. (2016) A Systematic Review of Supply Chain Knowledge Management Research: State of the Art and Research Opportunities. International Journal of Production Economics, 182, 276-292.

https://doi.org/10.1016/j.ijpe.2016.09.006

[11] Kolbachev, E., Kolbacheva, T. and Salnikova, Y. (2015) Application of Natural Science and Engineering Methods as a Trend in the Development of Economic and Management Research and Education. The Procedia-Social and Behavioral Sciences, 214, 1000-1007. https://doi.org/10.1016/j.sbspro.2015.11.692

[12] Balaman, Ş.Y. (2016) Investment Planning and Strategic Management of Sustainable Systems for Clean Power Generation: An $\mathcal{\varepsilon}$-Constraint Based Multi Objective Modelling Approach. Journal of Cleaner Production, 137, 1179-1190. https://doi.org/10.1016/j.jclepro.2016.07.202

[13] Tseng, M.-L., Lim, M.K., Wong, W.-P., Chen, Y.-C. and Zhan, Y. (2016) A Framework for Evaluating the Performance of Sustainable Service Supply Chain Management under Uncertainty. International Journal of Production Economics, 195, 359-372.

[14] Zhao, R., Liu, Y., Zhang, N. and Huang, T. (2016) An Optimization Model for Green Supply Chain Management by Using a Big Data Analytic Approach. Journal of Cleaner Production, 142, 1085-1097.

[15] Calle, M., González-R, P.L., Leon, J.M., Pierreval, H. and Canca, D. (2014) Integrated Management of Inventory and Production Systems Based on Floating Decoupling Point and Real-Time Information: A Simulation Based Analysis. International Journal of Production Economics, 181, 48-57.

[16] Izmailov, A., Korneva, D. and Kozhemiakin, A. (2016) Effective Project Management with Theory of Constraints. Procedia-Social and Behavioral Sciences, 229, 96-103. https://doi.org/10.1016/j.sbspro.2016.07.118

[17] Zhu, Q., Feng, Y. and Choi, S.-B. (2017) The Role of Customer Relational Governance in Environmental and Economic Performance Improvement through Green Supply Chain Management. Journal of Cleaner Production, 155, 46-53.

[18] Cerdas, F., Kurle, D., Andrew, S., Thiede, S., Herrmann, C., Zhiquan, Y., Sze, L., Jonathan, C., Bin, S. and Kara, S. (2015) Science Direct Defining Circulation Factories-A Pathway towards Factories of the Future. Procedia CIRP, 29, 627-632. https://doi.org/10.1016/j.procir.2015.02.032 
[19] Olarte, C. and Pimentel, E. (2017) On Concurrent Behaviors and Focusing in Linear Logic. Theoretical Computer Science, 685, 46-64.

[20] Almomani, M.A., Aladeemy, M., Abdelhadi, A. and Mumani, A. (2013) A Proposed Approach for Setup Time Reduction through Integrating Conventional SMED Method with Multiple Criteria Decision-Making Techniques. Computers \& Industrial Engineering, 66, 461-469. https://doi.org/10.1016/j.cie.2013.07.011

[21] Adhvaryu, A.R. and Nyshadham, A. (2013) Health, Enterprise, and Labor Complementarity in the Household. Journal of Development Economics, 126, 91-111. https://doi.org/10.1016/j.jdeveco.2016.11.007

[22] Caliendo, M. and Mahlstedt, R. (2017) Unobservable, but Unimportant? The Relevance of Usually Unobserved Variables for the Evaluation of Labor Market Policies. Labour Economics, 46, 14-25. https://doi.org/10.1016/j.labeco.2017.02.001

[23] Snelgrove, J.L., Doraagala, R.F., Hofraan, G.L. and Wiencek, T.C. (1987) The Use of $\mathrm{U}_{3} \mathrm{Si}_{2}$ Dispersed in Aluminum in Plate-Type Fuel Elements for Research and Test Reactors. Argonne National Lab., IL, Oak Ridge National Lab., TN. https://doi.org/10.2172/5688807

[24] Finlay, M.R., Hofman, G.L. and Snelgrove, J.L. (2004) Irradiation Behaviour of Uranium Silicide Compounds. Journal of Nuclear Materials, 325, 118-128. https://doi.org/10.1016/j.jnucmat.2003.11.009

[25] Olivares, L. (2013) Manufacture of Nuclear Fuel Elements in Chile.

[26] Simnad, M.T. (1981) Perspective on Research Reactors and Their Fuel Elements. Journal of Nuclear Materials, 100, 78-92. https://doi.org/10.1016/0022-3115(81)90523-7

[27] IAEA (2009) Good Practices for Qualification of High Density Low Enriched Uranium Research Reactor Fuels. Austria.

[28] Kim, Y.S., Hofman, G.L., Rest, J. and Robinson, A.B. (2009) Temperature and Dose Dependence of Fission-Gas-Bubble Swelling in $\mathrm{U}_{3} \mathrm{Si}_{2}$. Journal of Nuclear Materials, 389, 443-449. https://doi.org/10.1016/j.jnucmat.2009.02.037

[29] Gan, J., Keiser, D.D., Miller, B.D., Jue, J.F., Robinson, A.B., Madden, J.W., Medvedev, P.G. and Wachs, D.M. (2011) Microstructure of the Irradiated $\mathrm{U}_{3} \mathrm{Si}_{2} / \mathrm{Al}$ Silicide Dispersion Fuel. Journal of Nuclear Materials, 419, 97-104. https://doi.org/10.1016/j.jnucmat.2011.07.030

[30] Saliba-Silva, A.M., de Carvalho, E.F.U., Riella, H.G., Durazzo, M. and Urano de Carvalho, E.F. (2011) Research Reactor Fuel Fabrication to Produce Radioisotopes. InTech.

[31] Durazzo, M. and Riella, H.G. (2015) Procedures for Manufacturing Nuclear Research Reactor Fuel Elements. OmniScriptum GmbH \& Co. KG, Saarbrücken, Germany.

[32] Uygun, Ö. and Dede, A. (2016) Performance Evaluation of Green Supply Chain Management Using Integrated Fuzzy Multi-Criteria Decision Making Techniques. Computers \& Industrial Engineering, 102, 502-511. https://doi.org/10.1016/j.cie.2016.02.020

[33] Vasilecas, O., Kalibatiene, D. and Lavbi, D. (2016) Rule- and Context-Based Dynamic Business Process Modelling and Simulation. Journal of Systems and Software, 122, 1-15. https://doi.org/10.1016/j.jss.2016.08.048

[34] Zhang, L.L., Lee, C. and Zhang, S. (2016) An Integrated Model for Strategic Supply Chain Design: Formulation and ABC-Based Solution Approach. Expert Systems with Applications, 52, 39-49. https://doi.org/10.1016/j.eswa.2015.12.035 
[35] Diallo, S. and Mustafee, N. (2015) Towards an Encyclopedia of Modeling and Simulation Methodology. 2015 Winter Simulation Conference (WSC), Huntington Beach, CA, 6-9 December 2015, 2692-2703.

[36] Kouki, M., Cardin, O., Castagna, P. and Cornardeau, C. (2017) Input Data Management for Energy Related Discrete Event Simulation Modelling. Journal of Cleaner Production, 141, 194-207. https://doi.org/10.1016/j.jclepro.2016.09.061

[37] Qin, F., Mai, F., Fry, M.J. and Raturi, A.S. (2016) Supply-Chain Performance Anomalies: Fairness Concerns under Private Cost Information. European Journal of Operational Research, 252, 170-182. https://doi.org/10.1016/j.ejor.2016.01.033

[38] Baril, C., Gascon, V., Miller, J. and Côté, N. (2016) Use of a Discrete-Event Simulation in a Kaizen Event: A Case Study in Healthcare. European Journal of Operational Research, 249, 327-339. https://doi.org/10.1016/j.ejor.2015.08.036

[39] Dias, L.M.S., Pereira, G.A.B., Vik, P. and Oliveira, J.A. (2011) Discrete Simulation Tools Ranking.

https://repositorium.sdum.uminho.pt/bitstream/1822/15634/1/ISC_2011_Veneza_5 10.pdf

[40] Rockwell Automation (2015) Arena Simulation Software. https://www.arenasimulation.com/

[41] CNEN (1980) Standard CNEN 1.09-Safety of Factories of Fuel Elements. Comissão Nacional de Energia Nuclear, Rio de Janeiro, RJ.

[42] CNEN (2002) Standard CNEN 1.04-Licensing of Nuclear Facilities. Comissão Nacional de Energia Nuclear, Rio de Janeiro, RJ.

[43] IAEA (2006) The Management System for Facilities and Activities. IAEA Safety Standards Series No. GS-R-3, International Atomic Energy Agency. 